\title{
The effect of "imaging” on mirror image drawing
}

\author{
ANTHONY D. LUTKUS \\ Rutgers - The State University, Newark, New Jersey 07102
}

\begin{abstract}
Four groups practiced mirror tracing either a diamond or a zig-zag of equal length under either standard or imagery instructions. Imaging led to faster times and fewer errors. The diamond benefited more in the imagery condition than the zig-zag. The locus of the facilitation was found to be a reduction of errors at the turning points (apexes) of the diamond under imaging as opposed to standard instructions.
\end{abstract}

Easily imaged (i.e., concrete) nouns are remembered better than nouns that do not easily evoke an image (Paivio, 1971). Instructions to form images likewise have facilitative effects on mental operations such as memory for paired associates (Bower, 1972). Mental "practice," which miy be regarded as a form of imagery, has been shown to be effective in the acquisition of such motor skills as passing a volleyball or pursuit tracking (Hall, 1971; Johnson, 1971; Powell, 1973). The effect of such imaging practice on a motor skill is usually found when the practice period and the task are conducted separately. If the skill to be acquired involves adaptation to reversals in visual feedback, such as those found in the mirror drawing task, it was hypothesized that imaging the figure to be traced during the task would be an efficient learning strategy. This is a task-specific prediction. It is somewhat contrary to Brooks' (1967; 1968) general finding that using the visual system both in imaging and in the response mode results in impaired performance compared with using different modalities for the mental operation and the response.

\section{METHOD}

\section{Subjects}

The subjects were 64 underclassmen from Princeton University. They were equally divided by sex. All were right-handed.

\section{Apparatus}

A standard mirror-drawing apparatus (Woodworth \& Schlosberg, 1954; Starch, 1910) shielded the subject's hand from his line of sight and allowed him to see the outline of the figure he was tracing only in mirror image.

\section{Procedure}

The subjects were randomly divided into four groups in a 2 by 2 design. Half received standard instructions to trace the mirrored figure as quickly and accurately as possible. The other group was instructed to "image" the figure and to let their image guide their tracing as much as possible. Two figures, a diamond with 2 -in. sides and a zig-zag made up of line segments and angles equal to the diamond were used. A given subject traced only one

The author wishes to thank David Hedges, Cheryl Bass, John Flannery and J. Blair Richardson of Princeton University for their assistance in collecting data. This paper is sponsored by John Ceraso who takes full editorial responsibility for its contents.
Table 1

\begin{tabular}{|c|c|c|c|c|c|}
\hline \multicolumn{2}{|c|}{ Mean Tracing } & Times (S & conds) & and Errors & \\
\hline & & \multicolumn{2}{|c|}{ Times } & \multicolumn{2}{|c|}{ Errors } \\
\hline & & Standard & Image & Standard & Image \\
\hline Zig-Zag & $\begin{array}{l}\text { Mean } \\
\text { SD }\end{array}$ & $\begin{array}{l}51.9 \\
30.3\end{array}$ & $\begin{array}{l}30.2 \\
18.7\end{array}$ & $\begin{array}{r}14.08 \\
6.72\end{array}$ & $\begin{array}{r}12.32 \\
6.32\end{array}$ \\
\hline Diamond & $\begin{array}{l}\text { Mean } \\
\text { SD }\end{array}$ & $\begin{array}{l}76.9 \\
62.8\end{array}$ & $\begin{array}{l}37.6 \\
28.3\end{array}$ & $\begin{array}{l}22.16 \\
15.12\end{array}$ & $\begin{array}{r}10.72 \\
7.84\end{array}$ \\
\hline
\end{tabular}

of the figures for 10 trials in either the Imagery or Standard condition. Both time and errors were recorded for each trial. Errors were defined as touching or tracing outside the 1/8-in. wide path made by the double outline of the figure to be traced. Positions of the errors were recorded by numbering the parts of each figure and counting the errors within each subsection. The apex of the diamond, for example, was \#1, the first line segment $\# 2$, and so on.

\section{RESULTS}

Analyses of variance (Figure by Condition by Trials) were calculated for both the time and error measures. The image instructed groups were significantly faster $[F(1,60)=9.94, p<.01]$ and made fewer errors $[F(1,60)=7.34, p<.01]$. As would be expected with a motor task, the practice effect was highly significant $[F(9,540)=27.5, p<.001]$. Practice interacted with the type of Condition in that the Imagery groups began with much faster times than the Standard groups and then the gap was narrowed as the Standard groups improved over trials $[F(9,540)=3.54, p<.001]$. Table 1 presents mean times and errors for all four groups, averaged over the 10 trials.

The error data showed that the diamond benefited most from the imagery condition, i.e., the Figure by Condition interaction was significant $[F(1,60)=4.01$, $p<.05]$. When the errors were analyzed as a function of their position on either the diamond or zig-zag, there was a significant three-way $[F(7,420)=2.27, \mathrm{p}<.05]$ interaction (Figure by Condition by Position). Imagery instructions had little effect on the positions of the errors in the zig-zag but substantial effects on certain positions of the diamond. Graphing the error locations on the diamond within the three-way interaction 
revealed that under imagery instructions, errors at the turning points were drastically reduced compared with their numbers at the same points on the diamond without imagery instructions.

\section{DISCUSSION}

The results indicate that an induced imagery strategy can have a facilitative effect in the acquisition of a psychomotor skill such as mirror tracing. In addition, the locus of the imagery effect was identified as a reduction in errors made at the turning points. This was specific, however, to the diamond, possibly because it may have been the more easily imaged figure. Familiarity, meaningfulness, closedness, and symmetry are dimensions which may effect the ease with which a figure may be imaged. In pilot work. two additional figures were explored, a five-pointed star and a five-sided club equated for length of perimeter with the star. Imagery instructions were again superior to standard instructions but there was no difference between the figures. The observed facilitation of the diamond over the zig-zag may thus be related to the closed vs. open dimension. The interaction between the "imagability" of a figure and the facilitation of tracing it under imagery conditions is a topic for further research.

\section{REFERENCES}

Bower, G. H. Mental imagery and associate learning. In L. W. Gregg (Ed.), Cognition in learning and memory. New York: Wiley, 1972, Pp., 51-88.

Brooks, L. R. The suppression of visualization by reading. Quarterly Journal of Experimental Psychology, 1967, 19, 289-299.

Brooks, L. R. Spatial and Verbal components of the act of recall. Canadian Journal of Psychology, 1968, 22, 349-368.

Hall, R. G. The imaginal and verbal components in the acquisition of a perceptual motor skill. Unpublished doctoral dissertation, Washington State University, 1971.

Johnson, J. E. Effects of Imagery on learning the volleyball pass. Unpublished doctoral sissertation. Temple Univeristy, 1971.

Paivio, A. Imagery and verbal processes. New York: Holt, 1971.

Powell, G. E. Negative and positive mental practice in motor skill acquisition. Perceptual and Motor Skills, 1973, 37, 312.

Starch, D. A demonstration of the trial and error method of learning. Psychological Bulletin, 1910, 7. 20-23.

Woodworth, R. S., \& Schlosberg, N. Experimental psychology. New York: 1954, Pp. 741-743.

(Received for publication January 10, 1975.) 